\title{
Comparison of the Quality of the Chicken Breasts from Organically and Conventionally Reared Chickens
}

\author{
Dong-Hun Kim¹, Soo-Hyun Cho', Jin-Hyoung Kim¹, Pil-Nam Seong ${ }^{1}$, Jong-Moon Lee ${ }^{1}$, \\ Cheorun $\mathrm{Jo}^{2}$, and Dong-Gyun Lim* \\ Korea Livestock Products HACCP Accreditation Service, Anyang, 430-731, Korea \\ ${ }^{1}$ Animal Product and Processing, National Institute of Animal Science, RDA, Suwon 441-706, Korea \\ ${ }^{2}$ Department of Animal Science and Biotechnology, Chungnam National University, Daejeon 305-764, Korea
}

\begin{abstract}
In this study, the quality of chicken breasts from organically reared chickens was compared with that of chicken breasts from conventionally reared chickens. Broilers were raised in an indoor pen with conventional and organic production system, respectively. The diet formulation for the organically reared chickens and the production density were in accordance with the guidelines for organic chicken products. Twenty birds from each group were slaughtered and their breasts were obtained for analysis. The organic chicken breasts had a higher cooking loss, and waterholding capacity, and a lower shear force $(p<0.05)$ compared to the conventional chicken breasts. The organic chicken breasts also showed higher $\mathrm{a}^{*}$ and $\mathrm{b}^{*}$ values and myoglobin contents compared with the conventional chicken breasts $(p<0.05)$. In the fatty-acid analysis, the organic chicken breasts resulted in higher polyunsaturated fatty acid (PUFA) and unsaturated fatty acid contents, and a higher PUFA-saturated fatty acid ratio.
\end{abstract}

Key words : conventional, organic, fatty-acid composition, meat quality

\section{Introduction}

The recent crises related to livestock production such as bovine spongiform encephalopathy (BSE), avian influenza (AI), dioxin, and foot and mouth disease have frightened the consumers (Kouba, 2003). From this point, an increasing number of consumers' demand for health and natural foods has favoured organic livestock farming, which is considered to be environmentally friendly, raising animals in good health, with high welfare standards and resulting in high quality products (Sundrum, 2001).

In contrast to conventional livestock production, organic livestock farming is defined by basic guidelines. The guidelines have been formulated and further developed by the International Federation of Organic Agriculture Movements (IFOAM, 1996) and the European Union in EU regulations (EC, 1999). EU regulations on organic livestock production include concerns on the environment, production safety, and animal welfare (EC, 1999).

*Corresponding author : Dong-Gyun Lim, Korea Livestock Products HACCP Accreditation Service, Anyang 430-731, Korea. Tel: 82-31-390-5237, Fax: 82-31-465-6698, E-mail: elpollo9@snu.ac.kr
Major differences exist between organic and conventional production systems including housing, nutrition and management procedures (Millet et al., 2005). Organic farming restricts the use of pharmaceuticals, animal by-products, and genetically modified feed ingredients (Jahan $e t$ al., 2005). Also, organic feeds must consist of a minimum of $80 \%$ of ingredients produced in accordance with the rules of organic farming (Millet et al., 2005). Organic chickens are less intensively reared with free access to pastures and forages, thus perceived "natural" (Davies et al., 1995). Hovi et al. (2003) stated that organic layer production was relatively rapid, whereas organic broiler production was slower to develop, possibly due to the difficulty of finding suitable broiler breeds that would meet the organic requirements for slow growth and ability to range. Conventional chickens are typically fattened and confined to cages or barns and corn-fed poultry are reared on maize-based diets (Jahan et al., 2005).

Many consumers pay a premium to purchase chicken breasts and make value judgements related to animal welfare standards or organic production (Mintel, 1996; Harper and Makatouni, 2002). Consumers demand organic chicken by value systems favoring natural production, but may consider such products superior over conventional system 
due to its environmentally-friendly image (McEachern and Willock, 2004). The texture and color of meat are primary quality traits considered by consumers when making purchase choices regardless of rearing methods. The different feeds used in organic and conventional production systems may influence quality and fatty acid composition in chicken meat (Asghar et al., 1990). However, there is little information available on the meat quality between the chicken reared by conventional and organic method. Therefore, the objective of the study was to compare the meat quality of chicken breast reared by organically with those reared by conventionally.

\section{Materials and Methods}

\section{Animal and experimental design}

One-day-old commercial chicks (commercial cross breed) including male and female broilers were assigned to one of two housing conditions. Difference between conventional and organic farming was focused on feeding system and housing conditions in this study. For conventional production, 20 birds were randomly assigned in indoor pen $\left(0.05 \mathrm{~m}^{2} / \mathrm{bird}\right)$ with 5 birds/pen, whereas another 20 birds were assigned similarly to indoor pens but with different production density $\left(0.13 \mathrm{~m}^{2} / \mathrm{bird}\right)$ for organic production. The production density of organic farming was based on the National Regulation on Korean Organic Farming Standard which stated as $0.07 \mathrm{~m}^{2} /$ bird (Ministry for Food, Agriculture, Forestry and Fisheries, 2003). All birds were housed only in indoor area for $40 \mathrm{~d}$ until slaughtering. The surface in the conventional and organic pens covered with straw litter and slats were replaced weekly. Chickens were fed ad libitum the diets and water. The conventional diet was formulated with common ingredients according to the standard recommendations whereas the organic diet was composed of more than $80 \%$ of certified organic ingredients, which was manufactured in accordance with the Korean Organic Farming Standard (Ministry for Food, Agriculture, Forestry and Fisheries, 2003). The main difference in feed formulation was the absence of growth promoter and antibiotics in organic diet. The calculated nutrient and fatty acid composition of experimental diets for conventional and organic method are presented in Table 1.

All birds were slaughtered after $40 \mathrm{~d}$ of rearing at the commercial poultry slaughterhouse. The live weights of the birds were similar (approximately $1.5 \mathrm{~kg}$ ). The birds were stunned by an automatic electrical stunner and killed by manual exsanguinations, then plucked and evis-
Table 1. Calculated nutrient and fatty acid composition of the experimental diets

\begin{tabular}{lrr}
\hline \hline & Conventional diets & Organic diets \\
\hline Nutrients & & \\
Crude protein (\%) & 21 & 20 \\
Crude fat (\%) & 3 & 5 \\
Ash (\%) & 10 & 5 \\
Crude fiber (\%) & 6 & 5 \\
Ca (\%) & 0.96 & 0.8 \\
P (\%) & 1.4 & 0.6 \\
Methionine + Cystein (\%) & 0.8 & 0.7 \\
Calrorie (kcal/kg) & 3,050 & 2,950 \\
\hline Fatty acid composition (\%) & & \\
SFA & 27.74 & 26.19 \\
USFA & 72.26 & 73.81 \\
MUFA & 44.67 & 40.33 \\
PUFA & 27.59 & 33.48 \\
n-3 & 0.93 & 1.46 \\
n-6 & 26.66 & 32.02 \\
n-6/n-3 & 28.58 & 21.96 \\
MUFA/SFA & 1.61 & 1.54 \\
PUFA/SFA & 0.99 & 1.28 \\
\hline
\end{tabular}

${ }^{11}$ SFA, USFA, MUFA and PUFA refer to saturated, unsaturated, monounsaturated and polyunsaturated fatty acid, respectively.

cerated. A total of 40 carcasses (20 conventional samples, 20 organic samples) were transported to a laboratory. Immediately chicken breast and thigh were removed and stored at $4^{\circ} \mathrm{C}$ for $1 \mathrm{~d}$ until analysis was started.

\section{Proximate composition and meat quality}

Skin of chicken samples was peeled off and moisture (oven-drying method), crude protein (micro Kjeldahl method), crude fat (the microwave-solvent extraction method), and ash of chicken breast were determined by using the methods of the AOAC procedure (1996). $\mathrm{pH}$ was measured using portable needle-tipped combination electrode (NWK binar pH-K21 CE, Germany) by putting the sensor needle into the center of chicken breasts. Color of chicken breast was measured using a Minolta Chroma Meter CR-300 (Osaka, Japan) after $30 \mathrm{~min}$ blooming at room temperature. It was standardized using standard black and white tiles and the color L* (lightness), $a^{*}$ (redness), and $b^{*}$ (yellowness) values were recorded. The myoglobin content was calculated from the reflectance curve using the modified method of Krzywicki (1979). Reflectance values at wavelengths not given by the 473 , 525 and $572 \mathrm{~nm}$ (UV 1600 PC, Shimadzu, Tokyo, Japan) were calculated using a linear interpolation.

Cooking loss was measured based on the weight loss of meat after cooking. The samples were put into a polyeth- 
ylene bag and sealed. The packages were then heated in a water bath for $30 \mathrm{~min}$ until the inner temperature achieved to $75^{\circ} \mathrm{C}$, cooled at room temperature for $30 \mathrm{~min}$, and weighed. Warner-Bratzler (WB)-shear force was measured using the cooked samples according to the method described by Wheeler et al. (2000). The sample was prepared a cubic form $(1.25 \times 2 \times 2 \mathrm{~cm})$ by cutting them perpendicularly to the fibre direction and Instron (model 4465, UK) equipped with a WB-shear. Water-holding capacity (WHC) was determined using a filter paper method by the procedure of Honikel et al. (1994). Briefly, $0.5 \mathrm{~g}$ of sample was placed on glass and filter paper was pressed from the top at $35-50 \mathrm{~kg} / \mathrm{cm}^{2}$ for $2 \mathrm{~min}$, and calculated using a planimeter (Planis EX 010396, Tamaya Tech. Inc., Japan). For sensory analysis, 8 trained sensory panelists were selected, and chicken breast sample were provided to the panelists. The sample in a polyethylene bag was cooked in a water bath to achieve the inner temperature at $75^{\circ} \mathrm{C}$. Diced $(2 \times 2 \times 2 \mathrm{~cm})$ chicken breast with water and no salted snack in between the test to remove remaining flavor were servedto panelists. The sensory parameters were juiciness, tenderness and aroma. A 6-point hedonic scale, where a score of 6 represented "extremely like" and a score of 1 represented "extremely dislike", was used for sensory evaluation.

\section{Fatty acid composition}

The fatty acid composition was determined using the lipids extracted from chicken breast samples (about $5 \mathrm{~g}$ ) by homogenizing the sample with $20 \mathrm{~mL}$ of chloroformmethanol (2:1, v/v) according to the procedure of Folch et al. (1957). The sample mixture was filtered through a Whatman No. 1 filter paper (Advantec TOYO Roshi Kaisha, Japan). An aliquot of total lipid extract was methylated as described by Morrison and Smith (1964) and the prepared fatty acid methyl esters were analyzed by a gas chromatograph (Varian Model 3600, USA) fitted with a fused silica capillary column (Omegawax 320, $30 \mathrm{~m} 0.32$ $\mathrm{mM}$ ID, $0.25 \mu \mathrm{m}$ film thickness). The temperature of injection port and detector were $250^{\circ} \mathrm{C}$ and $300^{\circ} \mathrm{C}$, respectively. Results were expressed as percentages of individual fatty acid, which was identified by fatty acid standard (Sigma Co., Ltd, St. Louis, MO, USA), over total fatty acid based on peak area.

\section{Statistical analysis}

A randomized block design was used for this study and Analysis of Variance was performed using a statistical analysis system (1997). Student t-test was used to compare dif- ferences between mean values with significance level at $p<0.05$. Mean values and standard deviation were reported.

\section{Results and Discussion}

\section{Proximate composition and meat quality}

Proximate composition and meat quality of the chicken breast produced from the chicken reared by conventional and organic methods are shown in Table 2. Moisture, crude fat and crude protein contents were not different between the two groups (Table 2). Only crude ash were higher in the chicken breast from conventionally reared chicken than that of the organically reared one $(p<0.05)$. This higher ash contents in breast from conventional animals is difficult to explain and is seldom reported in the literature, especially for chicken breast. Previous studies have shown that the breast muscles of organic chickens had higher moisture and lower crude fat than those of conventional one (Castellini et al., 2002). Olsson et al. (2003) also reported that crude protein was significantly higher in meat from the organically produced pigs.

$\mathrm{pH}$ value had no difference between the chicken breast produced from conventional and organic method (Table 2). However, cooking loss and water holding capacity (WHC) were higher in the chicken breast with organic method than that with conventional one $(p<0.05)$. Generally, cooking loss and WHC is negatively correlated but previous studies indicated that a production system did not affect ultimate $\mathrm{pH}$, and the decreased WHC was

Table 2. Proximate composition and quality of the breast meat produced from the chicken reared by conventional and organic method

\begin{tabular}{lcc}
\hline \hline & Conventional $^{1)}$ & Organic \\
\hline Proximate composition (\%) & & \\
Moisture & $76.08 \pm 0.08$ & $76.15 \pm 0.11$ \\
Crude fat & $0.29 \pm 0.09$ & $0.17 \pm 0.01$ \\
Crude protein & $22.47 \pm 0.14$ & $22.75 \pm 0.11$ \\
Crude ash & $1.17 \pm 0.03^{\mathrm{a}}$ & $0.94 \pm 0.01^{\mathrm{b}}$ \\
\hline Physico-chemical analysis & & \\
pH & $6.13 \pm 0.04$ & $6.20 \pm 0.05$ \\
Cooking loss (\%) & $18.29 \pm 0.34^{\mathrm{b}}$ & $21.57 \pm 0.37^{\mathrm{a}}$ \\
Shear force (kg) & $1.58 \pm 0.04^{\mathrm{a}}$ & $1.34 \pm 0.04^{\mathrm{b}}$ \\
WHC (\%) & $62.56 \pm 0.43^{\mathrm{b}}$ & $63.99 \pm 0.38^{\mathrm{a}}$ \\
\hline Sensory analysis & & \\
Juiciness & $4.43 \pm 0.10$ & $4.40 \pm 0.08$ \\
Tenderness & $4.74 \pm 0.08$ & $4.74 \pm 0.09$ \\
Aroma & $4.56 \pm 0.06$ & $4.56 \pm 0.06$ \\
\hline
\end{tabular}

$\overline{\mathrm{a}, \mathrm{b}}$ Means \pm SE with different superscript within a row are significantly different $(p<0.05)$

${ }^{1)} \mathrm{n}=20$. 
explained by the slightly changed muscle traits of the exercised outdoor animals (Nilzen et al., 2001; Sather et al., 1997). In contrast, Castellini et al. (2002) reported that the $\mathrm{pH}$ and $\mathrm{WHC}$ were lower in organic broiler while cooking loss was higher compared with conventional one. Therefore, further study is needed to elucidate these contradictory results. For shear forces, the breast from organic chickens had a lower value than conventional one ( $p<$ 0.05). Castellini et al. (2002) found that the shear force values had higher in the breast or drumstick from the organic chickens, presumably as a consequence of their greater motor activity, which was not consistent with our result. Farmer et al. (1997) observed the same tendency for breast meat from birds reared under a lower stocking density. The shear forces measurement may give a good estimate of tenderness and texture profile. In the sensory evaluation, the chicken breast meat from two production systems was not different. Josäll et al. (2002) reported that a consumer preference test showed no significant difference between the organically and conventionally produced meats. However, the authors found that loins from the organically raised animals were less juicy but production system did not affect off-odour, acidulous taste, offtaste or tenderness. Lawlor et al. (2003) did not find any evidence that broiler breast meat from an organic source tasted better than free-range or conventionally produced broilers. On the other hand, Horsted et al. (2005) reported that sensory panel test gave significantly higher scores for juiciness and overall acceptability for the breast muscles from organic broilers.

Comparisons of meat color and myoglobin content of the chicken breast between two production systems are shown in Table 3. The breast of the organically reared broilers showed a higher CIE a* (red) and $b^{*}$ (yellow) values and a lower $\mathrm{L}^{*}$ (lightness) value than those of the conventionally reared ones. These results are consisted with those of the previous research that the meat of the

Table 3. CIE Color and myoglobin content of the breast meat produced from the chicken reared by conventional and organic method

\begin{tabular}{lrr}
\hline & Conventional $^{1)}$ & Organic \\
\hline Myoglobin content $(\mathrm{mg} / \mathrm{g})$ & $0.35 \pm 0.01^{\mathrm{b}}$ & $0.44 \pm 0.01^{\mathrm{a}}$ \\
\hline Color value & & \\
$\mathrm{L}^{*}$ & $54.14 \pm 0.67^{\mathrm{a}}$ & $52.09 \pm 0.44^{\mathrm{b}}$ \\
$\mathrm{a}^{*}$ & $3.31 \pm 0.20^{\mathrm{b}}$ & $3.90 \pm 0.14^{\mathrm{a}}$ \\
$\mathrm{b}^{*}$ & $1.90 \pm 0.18^{\mathrm{b}}$ & $5.38 \pm 0.30^{\mathrm{a}}$ \\
\hline
\end{tabular}

\footnotetext{
${ }^{\mathrm{a}, \mathrm{b}}$ Means \pm SE with different superscript within a row are significantly different $(p<0.05)$

1) $\mathrm{n}=20$.
}

organically reared pigs showed a higher redness and yellowness (Millet et al., 2004; Le Roy et al., 2000). However, Castellini et al. (2002) found that $\mathrm{L}^{*}$ and $\mathrm{b}^{*}$ of the breast muscles of the organic broilers were lower. Many studies observed no difference in meat color $\left(\mathrm{L}^{*}, \mathrm{a}^{*}\right.$ and $b^{*}$ ) between conventional and organic chickens (Olsson et al., 2003; van der Wal et al., 1993; Gentry et al., 2002). Warriss et al. (1983) observed slightly darker meat color as a consequence of outdoor raising. Sather et al. (1997) found slightly paler or less red pork from free-range raised pigs compared to conventionally raised animals. The darker (redder) color of organically reared animals could probably be attributed to an enlarged spontaneous activity, leading to an increased mean fiber cross-sectional area (Petersen et al., 1998). The breast of organic chickens had a higher content of myoglobin compared with those of conventional ones $(p<0.05)$. This is probably caused by higher activity or exercise of organic chickens and also consistent with the results of higher $a^{*}$ value. In the present experiment, production system affects some meat quality such as meat color. However, further investigations should be studied to clarify the relationship between organic feeding and meat quality.

\section{Fatty acid composition}

The fatty acid profile of chicken breast from organically and conventionally reared broilers is shown in Table 4. A higher levels of $\mathrm{C} 18: 2 \mathrm{n} 6, \mathrm{C} 18: 3 \mathrm{n} 6, \mathrm{C} 18: 3 \mathrm{n} 3$, and $\mathrm{C} 22: 4 \mathrm{n} 6$ in the breast produced from organically reared chicken were found than those of conventionally reared one $(p<0.05)$. The proportion of saturated fatty acid (SFA) and monounsaturated fatty acid (MUFA) was significantly lower while that of total unsaturated fatty acid (USFA) and polyunsaturated (PUFA) was significantly higher $(p<0.05)$ in the breast from organic production $(p<0.05)$. The importance of $\mathrm{n}-6 / \mathrm{n}-3$ ratio is recognized since the fatty acid C18:2 n- 6 and C18:3 n-3 are precursors of their longer homologues, as well as of different eicosaenoids, which have been shown to be of physiological importance (Horrocks and Yeo, 1999; Sardesai, 1992). In the case of organic chickens, the proportion of PUFA/SFA was significantly higher, whereas the proportion of $n-6 / n-3$ ratio and MUFA/SFA was significantly lower $(p<0.05)$. These results are consisted with those of the previous research that pigs reared organically had a higher content of PUFA than those reared conventionally, while pigs reared organically had a lower content of SFA and MUFA than those reared conventionally (Hansen $e t$ al., 2006). Similarly, there were higher levels of C18:2n6 
Table 4. Fatty acid composition (\%) of the breast meat produced from the chicken reared by conventional and organic method

\begin{tabular}{lrr}
\hline \multicolumn{1}{c}{ Fatty acid $^{1)}$} & Conventional $^{2)}$ & \multicolumn{1}{c}{ Organic $^{2}$} \\
\hline C14:0 (myristic) & $1.12 \pm 0.02^{\mathrm{a}}$ & $0.58 \pm 0.01^{\mathrm{b}}$ \\
C16:0 (palmitic) & $25.32 \pm 0.14^{\mathrm{a}}$ & $20.83 \pm 0.26^{\mathrm{b}}$ \\
C16:1n7 (palmitoleic) & $7.22 \pm 0.22^{\mathrm{a}}$ & $4.51 \pm 0.10^{\mathrm{b}}$ \\
C18:0 (stearic) & $6.05 \pm 0.13$ & $5.65 \pm 0.30$ \\
C18:1n9 (oleic) & $46.40 \pm 0.32^{\mathrm{a}}$ & $36.76 \pm 0.24^{\mathrm{b}}$ \\
C18:2n6 (linoleic) & $12.01 \pm 0.32^{\mathrm{b}}$ & $28.04 \pm 0.38^{\mathrm{a}}$ \\
C18:3n6 ( $\gamma$-linolenic) & $0.07 \pm 0.01^{\mathrm{b}}$ & $0.15 \pm 0.03^{\mathrm{a}}$ \\
C18:3n3 ( $\alpha$ - linolenic) & $0.71 \pm 0.02^{\mathrm{b}}$ & $2.52 \pm 0.05^{\mathrm{a}}$ \\
C20:1n9 (eicosenoic) & $0.19 \pm 0.02^{\mathrm{a}}$ & $0.07 \pm 0.00^{\mathrm{b}}$ \\
C20:2n6 (eicosadienoic) & $0.47 \pm 0.03^{\mathrm{a}}$ & $0.32 \pm 0.01^{\mathrm{b}}$ \\
C20:3n6 (eicosatrienoic) & $0.20 \pm 0.03$ & $0.19 \pm 0.00$ \\
C20:4n6 (arachidonic) & $0.21 \pm 0.04^{\mathrm{a}}$ & $0.13 \pm 0.00^{\mathrm{b}}$ \\
C22:4n6 (satetraenoic) & $0.02 \pm 0.01^{\mathrm{b}}$ & $0.24 \pm 0.01^{\mathrm{a}}$ \\
SFA & $32.49 \pm 0.17^{\mathrm{a}}$ & $27.06 \pm 0.25^{\mathrm{b}}$ \\
USFA & $67.51 \pm 0.17^{\mathrm{b}}$ & $72.94 \pm 0.25^{\mathrm{a}}$ \\
MUFA & $53.82 \pm 0.44^{\mathrm{a}}$ & $41.34 \pm 0.29^{\mathrm{b}}$ \\
PUFA & $13.69 \pm 0.38^{\mathrm{b}}$ & $31.60 \pm 0.43^{\mathrm{a}}$ \\
n-3 & $0.71 \pm 0.02^{\mathrm{b}}$ & $2.52 \pm 0.05^{\mathrm{a}}$ \\
n-6 & $12.98 \pm 0.36^{\mathrm{b}}$ & $29.07 \pm 0.39^{\mathrm{a}}$ \\
n-6/n-3 & $18.44 \pm 0.36^{\mathrm{a}}$ & $11.55 \pm 0.15^{\mathrm{b}}$ \\
MUFA/SFA & $1.66 \pm 0.02^{\mathrm{a}}$ & $1.53 \pm 0.02^{\mathrm{b}}$ \\
PUFA/SFA & $0.42 \pm 0.01^{\mathrm{b}}$ & $1.17 \pm 0.02^{\mathrm{a}}$ \\
\hline
\end{tabular}

$\overline{\mathrm{a}, \mathrm{b}}$ Means \pm SE with different superscript within a row are significantly different $(p<0.05)$

${ }^{1)}$ SFA, USFA, MUFA and PUFA refer to saturated, unsaturated, monounsaturated and polyunsaturated fatty acid, respectively.

2) $\mathrm{n}=20$.

and PUFA $\mathrm{n}-6$ in pigs fed organically than in pigs fed conventionally (Högberg et al., 2003). The higher content of PUFA in organically produced pigs may not only be a result of the different feed but also partly caused by the higher lean meat percentage (Hansen et al., 2006). In contrast to our results, Castellini et al. (2002) showed that the breast muscles of the organic chickens had a higher fraction of SFA and PUFA, while those of the organic ones had a lower MUFA. The previous research that the fatty acid composition of the intra muscular fat is affected by several factors, which diet in general seems to be one of the most important (Nürnberg et al., 1998). Olsson et al. (2003) suggested that the differences in fatty acid composition of the basal feed could be important than a contribution from grass, for the organically raised pigs, in determining the fatty acid composition of the meat. From these results, the difference in fatty acid composition between conventional and organic chickens may be mainly due to the consequence of different feed. The high contents of n-3 and n-6 PUFA may be due to the consequence of more containing feed such as soya bean meal and fish meal in organic feeds. However, a clear comparison between the meats reared by organic and conventional methods seemed difficult because meat quality is largely dependent on farm management.

From the limited number of published data, it seems that there is no clear evidence that organically produced chicken has a better quality than conventionally produced one. Further research should be needed on the causes of variability in fatty acid composition of chicken muscles to clarify the relationship between organic feeding and meat quality. However, it is certain that consumers' confidence on organic products is very important.

The production of chicken breast using an organic method may lead to differences in meat quality such as fatty acid composition and meat color. From the present study, it can be concluded that an organic production of chicken breast has no detrimental effect on meat quality and seems to be a possible alternative to the conventional one for consumer's preference.

\section{Acknowledgments}

This study was supported was supported by a grant from BioGreen 21 program, Rural Development Administration, Republic of Korea.

\section{References}

1. AOAC. (1996) Official Methods of Analysis. $16^{\text {th }}$ ed. Association of Official Analytical Chemists, Washington, DC, USA.

2. Asghar, A., Lin, C. F., Buckley, D. J., Booren, A. M., and Flegal, C. J. (1990) Effects of dietary oils and a-tocopherol supplementation on membranal lipid oxidation in broiler meat. J. Food Sci. 55, 46-50.

3. Castellini, C., Mugnai, C., and Dal, B. A. (2002) Effect of organic production system on broiler carcass and meat quality. Meat Sci. 60, 219-225.

4. Davies, A., Titterington, A. J., and Cochrane, C. (1995) Who buys organic food? A profile of the purchasers of organic food in Northern Ireland. Br. Food J. 97, 17-23.

5. EC (1999) Council Regulation (EC) No. 1804/1999 of 19 July 1999 supplementing Regulation (EEC) No. 2029/91 on organic production of agricultural products and indications referring thereto on agricultural products and foodstuffs to include livestock production. Official J. European Comm. 24. 98. Brussels. L. 222, 1-28.

6. Farmer, L. J., Perry, G. C., Lewis, P. D., Nute, G. R., Piggott, J. R., and Patterson, R. L. S. (1997) Responses of two genotypes of chicken to the diets and stocking densities of conventional UK and Label Rouge production systems - II. Sensory Attributes. Meat Sci. 47, 77-93.

7. Folch, J., Lee, M., and Sloan-Stanley, G. H. (1957) A simple 
method for the isolation and purification of total lipids from animal tissue. J. Biol. Chem. 226, 497.

8. Gentry, J. G., McGlone, J. J., Blanton, J. R., and Miller, M. F. (2002) Impact of spontaneous exercise on performance, meat quality and muscle fibre characteristics of growing/finishing pigs. J. Anim. Sci. 80, 2833-2839.

9. Hansen, L. L., Claudi-Magnussen, C., Jensen, S. K., and Andersen, H. J. (2006) Effect of organic pig production systems on performance and meat quality. Meat Sci. 74, 605-615.

10. Harper, G. C. and Makatouni, A. (2002) Consumer perception of organic food production and farm animal welfare. $\mathrm{Br}$. Food J. 104, 287-299.

11. Högberg, A., Pickova, J. K. A, and Lundström, K. (2003) Fatty acid composition and tocopherol content of muscle in pigs fed organic and conventional feed with different n6/n3 ratios, respectively. Food Chem. 80, 177-186.

12. Honikel, K. O., and Hamm, R. (1994) Advances in Meat Research. Vol. 9. A. M. Pearson and Dutson, T. R. (eds), Chapman and Hall, Glasgow, UK.

13. Horrocks, L. A. and Yeo, Y. K. (1999) Health benefits of docosahexaenoic acid (DHA). Pharma. Res. 40, 211-222.

14. Horsted, K., Henning, J., and Hermansen, J. E. (2005) Growth and sensory characteristics of organically reared broilers differing in strain, sex and age at slaughter. Acta Agric. Scand Sec. A. 55, 149-157.

15. Hovi, M., Sundrum, A., and Thamsborg, S. M. (2003) Animal health and welfare in organic livestock production in Europe: current state and future challenges. Livest. Prod. Sci. 8, 41-53.

16. IFOAM. (1996) International Federation of the Organic Agriculture Movements: Basic Standards for Organic Agriculture and Food Processing. 10 ${ }^{\text {th }}$ Edition. SÖL, Bad Dürchhei.

17. Jahan, K., Paterson, A., and Piggott, J. R. (2005) Sensory quality in retailed organic, free range and corn-fed chicken breast. Food Res. Int. 38, 495-503.

18. Josäll, A., Johanson, L., Lundstrom, K., Anderson, K. H., Nilsen, A. N., and Risvik, E. (2002) Effects of genotype and rearing system on sensory characteristics and preference for pork. Food Quality Prefer. 13, 73-80.

19. Kouba, M. (2003) Quality of organic animal products. Livest. Sci. 80, 33-40.

20. Krzywicki, K. (1979) Assessment of relative content of myoglobin, oxymyoglobin and metmyoglobin at the surface of beef. Meat Sci. 3, 1-10.

21. Lawlor, J. B., Sheehan, E. M., Delahunty, C. M., Kerry, J. P., and Morrissey, P. A. (2003) Sensory characteristics and consumer preference for cooked chicken breasts from organic, corn-fed, free-range and conventionally reared animals. Int. J. Poultry Sci. 2, 409-416.

22. Le Roy, P., Elssen, J. M., Caritez, J. C., Talmant, A., Juin, H., Sellier, P., and Monin, G. (2000) Comparison between the three porcine genotypes for growth, carcass composition and meat quality traits. Genet. Sel. Evol. 32, 165-186.

23. McEachern, G. M. and Willock, J. (2004) Producers and consumers of organic meat: A focus on attitude and motivation. Br. Food J. 106, 534-552.
24. Millet, S., Hesta, M., Seynaeve, M., Ongenae, E., De Smet, S., Debraekeleer, J., and Janssens, G. P. J. (2004) Performance, meat and carcass traits of fattening pigs with orgnic versus conventional housing and nutrition. Livest. Sci. 87, 109-119.

25. Millet, S. C. E., Buyse, J., Goddeeris, B. M., and Janssens, G. P. J. (2005) Immunocompetence of fattening pigs fed organic versus conventional diets in organic versus conventional housing. Vet. J. 169, 293-299.

26. Ministry for Food, Agriculture, Forestry and Fisheries. (2003) National regulation on Korean organic farming standard.

27. Mintel (1996) Red meat. London, pp. 132.

28. Morrison, W. R. and Smith, L. M. (1964) Preparation of fatty acid methyl esters and dimethylacetals from lipids with boron trifluoride-methanol. J. Lipid Res. 5, 600-608.

29. Nilzen, V., Babol, J., Dutta, P. C., Lundeheim, N., Enfalt, A. C., and Lundstrom, K. (2001) Free range rearing of pigs with access to pasture grazing effect on fatty acid composition and lipid oxidation products. Meat Sci. 58, 267-275.

30. Nürnberg, K., Wegner, J., and Ender, K. (1998) Factors influencing fat composition in muscle and adipose tissue of farm animals. Livest. Prod. Sci. 56, 145-156.

31. Olsson, V., Andersson, K., Hansson, I., and Lundström. A. (2003) Differences in meat quality between organically and conventionally produced pigs. Meat Sci. 64, 287-297.

32. Petersen, J. S., Henckel, P., Oksbjerg, N., and Sorensen, M. T. (1998) Adaptions in muscle fibre characteristics induced by physical activity in pigs. J. Anim. Sci. 66, 733-740.

33. Sardesai, V. M. (1992) Biochemical and nutritional aspects of eicosanoids. J. Nutr. Biochem. 3, 562-579.

34. SAS (1997) SAS/STAT Software for PC, SAS Institute INC, Cary, NC, USA.

35. Sather, A. P., Jones, S. D. M., Schaefer, A. L., Colyn, J., and Robertson, W. M. (1997) Feedlot performance, carcass composition and meat quality of free range reared pigs. Canadian J. Anim. Sci. 77, 225-232.

36. Sundrum, A., Bütfering, L., Henning, M., and Hoppenbrock, K. H. (2000) Effects of on-farm diets for organic pig production on performance and carcass quality. J. Anim. Sci. 78, 1199-1205.

37. Sundrum, A. (2001) Organic livestock farming. A critical review. Livest.Prod. Sci. 67, 207-215.

38. van der Wal, P. G., Mateman, G, de Vries, A. W., Vonder, G. M. A., Smulders, F. J. M., Geesink, G. H., and Engel, B. (1993) Free range pigs: carcass composition, meat quality and taste-panel studies. Meat Sci. 34, 27-37.

39. Warriss, P. D., Kestin, S. C., and Robinson, J. M. (1983) A note on the influence of rearing environment on meat quality in pigs. Meat Sci. 9, 271-279.

40. Wheeler, T. L, Shackelford, S. D., and Koohmaraie, M. (2000) Relationship of beef longissimus tenderness classes to tenderness of gluteus medius, semimembranosus, and biceps femoris. J. Anim. Sci. 78, 2856-2861.

(Received 2008.12.29/Revised 1st 2009.5.3, 2nd 2009.5.26/ Accepted 2009.5.27) 